\title{
A Rate of Passage
}

\section{Tim Maudlin}

New York University

Department of Philosophy

New York, New York

U.S.A.

twm3@nyu.edu

Article info

CDD: 115

Received: 23.03.2017; Accepted: 24.03.2017

DOI: http://dx.doi.org/10.1590/0100-6045.2017.V40N1.TM

Keywords

Passage of Time

Rate of Passage

Jonathan Tallant

'No alternate possibility' argument

\begin{abstract}
In "Temporal Passage and the 'No Alternate Possibilities Argument", Jonathan Tallant takes up one objection based on the observation that if time passes at the rate of one second per second there is no other possible rate at which it could pass. The argument rests on the premise that if time passes at some rate then it could have passed at some other rate. Since no alternative rate seems to be coherent, one concludes that time cannot pass at all. The obvious weak point of the NAP is the premise itself.
\end{abstract}

The nature, and indeed very existence, of the passage of time is one of the most peculiar topics in metaphysics. On the one hand, it is a firm and foundational part of common sense that time passes. The passage of time from past to future plays a definitional role in all actions and motions. A trip from north to south differs from a trip from south to north because in the one case one gets further south as time passes and in the other further north. Trying to excise the passage of time from our account of the world would require forgoing all motion and change. What is left could hardly be recognizable as the world we live in.

Manuscrito - Rev. Int. Fil. Campinas, v. 40, n. 1, pp. 75-79, jan.-mar. 2017. 
Nonetheless, claims are often made that the passage of time is either inconsistent with our best physical theories or conceptually incoherent. The appeals to science require discussion of relativity theory, or even some speculative theory of quantum gravity. The claims of conceptual incoherence advert to much simpler non-technical issues. Prominent among these are worries about the rate of time's passage. In a nutshell, it is claimed that if time passes it must pass at some rate, but there is no such rate, so time cannot pass.

In "Temporal Passage and the "No Alternate Possibilities Argument", Jonathan Tallant takes up one objection based on the observation that if time passes at the rate of one second per second there is no other possible rate at which it could pass. He calls it the No Alternative Possibilites (NAP) objection. The argument rests on the premise that if time passes at some rate then it could have passed at some other rate. Since no alternative rate seems to be coherent, one concludes that time cannot pass at all.

The obvious weak point of the NAP is the premise itself. Why should the existence of a rate of passage require the possibility of a different rate? As Tallant notes, I have elsewhere used the example of a fair rate of exchange. Whereas the fair rate of exchange between two different currencies can possibly take any number of values, the fair rate of exchange between any currency and itself is, necessarily, 1 for 1 . Tallant concedes this, but asserts that it is "beside the point" that there are no alternative possibilities for a fair rate of exchange since there are alternative possibilities for (possibly unfair) rates of exchange. But the point is just that a lack of alternative possibilities does not imply that there is anything wrong with the single necessary actuality. There are no alternative possibilities to the sum of 1 and 2 , but that hardly impeaches the truth or informativeness of the claim that $1+2=3$.

Tallant weakens the force of the NAP argument. Instead of proving the conceptual incoherence of time passing, Tallant's NAP* means to provide prima facie but defeasible grounds for rejecting time passing. Since other rates are contingent, Tallant claims, there would be something suspicious about a necessary rate. But it is hard to see what is suspicious about the rate of 1 second/second. True, it is not contingent, but it is easy to see how it differs from other rates. Adapting the example from section 5 , it is contingent whether anyone is as tall as his or her father, but not

Manuscrito - Rev. Int. Fil. Campinas, v. 40, n. 1, pp. 75-79, jan.-mar. 2017. 
contingent whether anyone is as tall as him- or herself. The reason for the contingency of the one and the necessity of the other is evident. Does that make the claim that John is as tall as himself controversial? Similarly, the reason why this particular rate is necessary while others are contingent is evident, so no suspicion accrues to the latter.

At the end of the day, it does not seem to be the argument of section 3 that really motivates Tallant's views, but rather the quite different consideration offered in this passage:

I deny that there are any good arguments to support the truth of the claim that 'time passes'. My reasoning is simple. Suppose that you are a dynamic theorist of time. You do not, then, think that there is a thing, time, that passes. Rather, you think that things change. Indeed, by I take you to be committed to the truth of the claim that 'certain times or events are absolutely present, and there is continual change in respect of which ones they are'. So be it. But that is not to say that time passes; for to say that time passes is to say that there is an entity, time, and that it performs an action: passing. And that is not something that any dynamic theorist (that I am aware of) has ever argued. ${ }^{1}$

The force of this argument, as I read it, derives from the claim that the subject/predicate sentence "Time passes" requires, for its truth, that the subject refer to an entity and the predicate to an action of the entity. And quite rightly, Tallant notes that no one ever argues that passing is an action and time an entity.

But if no one ever argued that and no one every held that, then what is expressed by the sentence "Time passes" presumably does not mean that time is an entity and passing an action of that entity. Tallant attempts to account for the phrase as hypallage, the transference of an attribute from its proper subject to another object. According to Tallant, the original and proper use of "passes" is transitive: one objects passes another, e.g. a feather floating on a river passes the root of a tree. This is a process that happens in time. It is claimed that this is the origin of the intransitive use: time passes.

${ }^{1}$ In the first part of this special issue, p. 44.

Manuscrito - Rev. Int. Fil. Campinas, v. 40, n. 1, pp. 75-79, jan.-mar. 2017. 
But this account of the origin of the phrase is unlikely to be true. In place of "passes" we could just as well have used "elapses", and "elapse" has no transitive use. Furthermore, just as "passes" in its intransitive use is applied only to time, so "elapses" applies only to time or periods of time. Passing or elapsing is a fundamental asymmetric dynamical feature of time that distinguishes it from space. Space extends, where extending is a symmetric notion: the space that extends from A to B equally extends from B to A. But the time that elapses from $10 \mathrm{AM}$ to noon does not equally elapse from noon to $10 \mathrm{AM}$.

The subject/predicate form of "Time passes" or "Time elapses" does not provide a clue, much less a requirement, for the metaphysical analysis of what the sentence asserts. The subject need not refer to a "thing" and the predicate to an "action" in order for the sentence to express a truth. In contrast, the unique application of the intransitive form of "pass" and of "elapse" to time indicates that there is a unique characteristic of time, a characteristic not shared by anything else. It is because of this unique character that time is often described using metaphors of moving and gliding and slipping by. Since all of these motions require time for their existence the metaphors cannot be really enlightening. This is just what one would expect for a metaphysically fundamental characteristic that cannot be further analyzed.

If the passage or elapsing of time cannot be analyzed into simpler or more basic components, can anything informative be said about it at all? The essence of time is successiveness, one thing happening after another in a fixed order. Newton took the ordered entities to be moments of universal time, each one spread out over all of space. Relativity takes them instead to be events, and the order to be a partial order. But the primary notion of successiveness and asymmetrical ordering remains. In this way temporal structure is fundamentally unlike spatial structure, so Relativity does not somehow reduce temporal structure to spatial.

Relativity does underwrite the quantification of elapsing time via the proper time of timelike worldlines. The interweaving of these lines determines the entire structure of the space-time. Once the temporal lengths, directions, and interrelations of these worldlines have been specified, nothing more can be offered concerning the structural characteristics of time. The temporal aspect of space-time is dynamical:

Manuscrito - Rev. Int. Fil. Campinas, v. 40, n. 1, pp. 75-79, jan.-mar. 2017. 
events along a single worldline occur in successive temporal order. Even in Relativity, time passes.

Manuscrito - Rev. Int. Fil. Campinas, v. 40, n. 1, pp. 75-79, jan.-mar. 2017. 